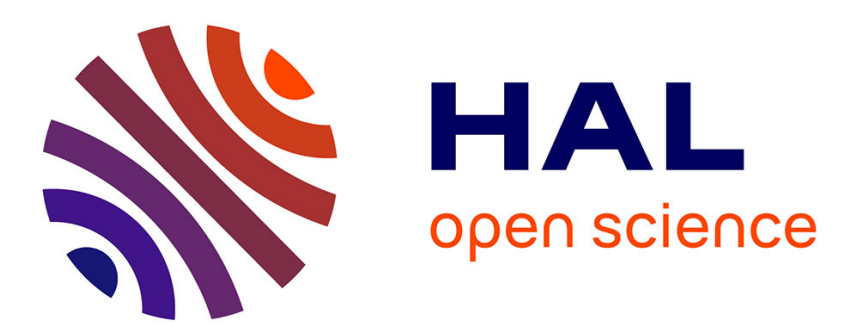

\title{
Quantification of soot deposit on a resistive sensor: proposal of an experimental calibration protocol
}

Amel Kort, F-X. Ouf, T. Gelain, J. Malet, Riadh Lakhmi, Philippe Breuil, Jean-Paul Viricelle

\section{To cite this version:}

Amel Kort, F-X. Ouf, T. Gelain, J. Malet, Riadh Lakhmi, et al.. Quantification of soot deposit on a resistive sensor: proposal of an experimental calibration protocol. Journal of Aerosol Science, 2021, 156, pp.105783. 10.1016/j.jaerosci.2021.105783 . emse-03203120

HAL Id: emse-03203120

https://hal-emse.ccsd.cnrs.fr/emse-03203120

Submitted on 20 Apr 2021

HAL is a multi-disciplinary open access archive for the deposit and dissemination of scientific research documents, whether they are published or not. The documents may come from teaching and research institutions in France or abroad, or from public or private research centers.
L'archive ouverte pluridisciplinaire HAL, est destinée au dépôt et à la diffusion de documents scientifiques de niveau recherche, publiés ou non, émanant des établissements d'enseignement et de recherche français ou étrangers, des laboratoires publics ou privés. 


\title{
Quantification of soot deposit on a resistive sensor: proposal of an experimental calibration protocol
}

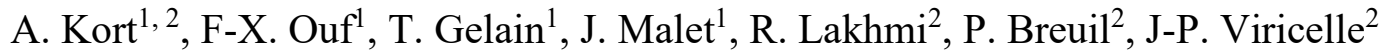 \\ ${ }^{1}$ Institut de Radioprotection et de Sûreté Nucléaire (IRSN), PSN-RES, SCA, Gif-sur-Yvette, \\ 91192, France \\ ${ }^{2}$ Ecole Nationale Supérieure des Mines, SPIN-EMSE, CNRS : UMR5307, LGF, 42023 Saint \\ Etienne, France
}

\begin{abstract}
During a fire in an industrial facility, the main consequences concerning aerosol are the production of large amount of soot and potential resuspension of hazardous material in particulate form. Soot deposition quantification on walls in a room during a fire is essential for the prediction of aerosol quantities that can be transported in the ventilation ducts and clog high efficiency particulate air filters.

For this purpose, accumulative resistive sensors, initially developed for monitoring Diesel Particulate Filters (DPF), have been used to quantify soot particles that are deposited on its sensing side. After validation of the fabrication process via electrical measurements, the sensor response has been studied under different polarization voltages and an experimental protocol for soot quantification has been qualified.

Thanks to those protocols, it was first demonstrated that the polarization voltage has no influence on the deposition velocity. Then, the resistive sensor was calibrated at polarization voltages of $10 \mathrm{~V}$ and $0.1 \mathrm{~V}$. For $0.1 \mathrm{~V}$, results are less repeatable and do not allow to propose a correlation between conductance and deposited mass. Better repeatability was found for a polarization voltage of $10 \mathrm{~V}$ allowing to propose and develop a calibration procedure aiming to correlate sensor conductance and deposited mass of aerosol.

Indeed, it was proved that the sensor has a blind zone, in terms of conductance, for mass deposit ranging from 0 to $230 \mathrm{mg} / \mathrm{m}^{2}$. A linear calibration curve with a good sensitivity of $2.49 \mu \mathrm{S} \cdot \mathrm{mg}^{-1} \cdot \mathrm{m}^{2}$ was obtained for deposited mass between 230 and $1630 \mathrm{mg} / \mathrm{m}^{2}$.
\end{abstract}

\section{KEYWORDS}

Resistive sensor, soot, polarization, conductance, quantification.

\section{INTRODUCTION}

According to the most recent fire statistics from the National Fire Protection Association (NFPA) (Campbell, 2018), an average of 37,000 fires occurs in industrial and manufacturing facilities every year, placing fire as one of the major hazards occurring in industrial facilities.

These fires have highlighted the need for a precise prediction of their consequences in terms of dispersion of hazardous materials potentially adsorbed at the surface of particles emitted in such situations and for a better understanding of the transport and deposition phenomenon of emitted particles. This has been already demonstrated during wildland fires of contaminated surroundings of the Chernobyl site (Chesser \& Rodgers. B.E., 2008) and Fukushima site (Kaltofen \& Gundersen, 2017). More recently, many dramatic fires ensued in France with significant societal impacts. As an example, fires of Notre Dame Cathedral (15-16 April 2019 in Paris, France) and Lubrizol chemical plant (26 September 2019 in Rouen, France) have demonstrated the need for a better prediction of toxicological consequences of such large scale outdoor fires on populations. Beyond the question of atmospheric dispersion and contamination of environment by fine particles, similar question is raised when considering consequences of fires on containment of hazardous materials (nuclear, biological, chemical) within industrial facilities (Evangeliou et al., 2016). In most cases, containment is ensured thanks to a ventilation network associated to High Efficiency Particulate Air (HEPA) filters to avoid any release of hazardous particles outside facilities. In order to predict the behavior of such containment devices in accidental fire scenario, several studies have been carried out on clogging of HEPA filters in case of fires (Bourrous et al., 2016; Ohno et al., 2020). In all these developments, the prediction of the amount of soot upstream of the HEPA filters are of main importance and, for this purpose, further improvement on simulation tools for predicting soot particles transport and deposition in confined and ventilated industrial facilities has to be done. In particular, the validation of particle deposit models implemented in Computational Fluid Dynamics codes (Floyd et al., 2014; Gelain et al., 2018) and used to assess the deposited mass of soot over time in a fire room, needs to be improved.

However, in the literature, there is a lack of quantitative soot deposition data under realistic fire conditions, due to the complexity of the fire phenomena on a real scale facility: the experimental data on deposited soot mass are limited to studies under controlled conditions on a small scale (Riahi, 2012) or based on basic devices (Bellivier et al., 2015). 
Therefore, relevant measurement devices should be developed for the real-time measurement of soot deposition on the walls of rooms experiencing fire scenario such as confined and poorly ventilated nuclear facility.

The accumulative soot sensors (Brunel et al., 2013; Fragkiadoulakis et al., 2018; Reynaud et al., 2019) present several advantages for soot quantification in a fire context. They are cheap, suitable for the harsh temperature and chemical environment and could be easily integrated on room walls during fire experiments. Among the accumulative soot sensors, resistive ones could be a promising solution since these sensors are already considered in the automotive field (Grondin at al., 2016) and have recently been used by Mensch \& Cleary (2018) for a first attempt to quantify soot deposits on surfaces under fire conditions.

In the present work, the resistive technology has been adopted for quantification of the soot particles deposit on the walls of a room under fire conditions which is, to the best of our knowledge, not yet allowed by any sensor from the literature. The principle of these sensors is based on the conductance increase induced by the soot deposit when a polarization voltage is applied (Grondin et al., 2016). Particle size on the selected polarization voltage has also an effect on the sensor response as described by (Grondin et al., 2016). Besides, (Fragkiadoulakis et al., 2018) have developed a model to predict the behavior of the sensor for a range of exhaust gas conditions, taking into account sensor geometry and (Hagen et al., 2018) discussed the internally caused thermophoresis in high voltages. Nevertheless despite the existence of numerous studies dealing with deposition mechanisms of soot particles on the resistive sensor, up to now, there is no way to retrieve, from the raw signal of the sensor, any quantitative information on accumulated mass of particles on the sensor surface. Beyond quantification, further studies on the potential influence of resistive sensor itself on soot deposition phenomenon are needed, especially on potential electrophoresis and di-electrophoresis effects (Reynaud, 2019) associated to the polarization voltage applied for measuring the sensor conductance. In order to consider the resistive sensor technology as a relevant and noninvasive method to characterize aerosol deposit on walls within a fire room, the aim of this paper is first to investigate the effect of polarization voltage of the sensor on the mass of deposited soot. Furthermore, this study also aims to introduce and qualify a methodology to correlate the soot mass deposited onto the active surface of the sensor and the corresponding sensor conductance value.

\section{DESCRIPTION OF THE SYSTEM}

\subsection{Sensor principle, fabrication process and validation}

For this study, the fabrication process and the design of the resistive sensor have been inspired from the previous work of Grondin et al., (2015). The resistive sensor has been manufactured in the laboratory thanks to the association of different screen-printing and laser engraving steps. It is composed of an alumina substrate $(52 \mathrm{~mm}$ $\times 5.1 \mathrm{~mm} \times 0.8 \mathrm{~mm})$ that supports the sensing element $(3.5 \mathrm{~mm} \times 3.5 \mathrm{~mm})$ on the front side and a heater element on the back side, both made of platinum. The sensing element (figure 1.a) is composed of interdigitated electrodes made by laser engraving (Technifor - G5 - LW1) of a platinum layer previously screen-printed on an alumina substrate (screen printing machine used: R-23 Meteor Semi-Automatic from REPRINT). A commercial platinum ink (ref. ESL5545) is used to form a rectangular pattern of approximately $3 \mathrm{~cm}^{2}$ on dense alumina substrates (Coorstek) with a thickness of $0.8 \mathrm{~mm}$. The electrodes are $40 \mu \mathrm{m}$ wide (W), the inter-electrode space (S) is $20 \mu \mathrm{m}$ and the electrodes length (L) is $3.5 \mathrm{~mm}$ (figure 1).

The sensor output is the conductance measured when a polarization voltage is applied between the two interdigitated platinum electrodes. This conductance is initially very low (below $1 \mathrm{nS}$ ) and corresponds to that of alumina. It increases consecutively with soot deposit between the electrodes.

The conductance measurement allows an indirect follow-up of the amount of soot deposited on the sensor (Bartscherer \& Moos, 2013; Feulner et al., 2015). In order to bring the sensor back to its initial conductance, the sensing face of the sensor (figure 1.a) is regenerated by burning the soot deposit at $650{ }^{\circ} \mathrm{C}$ thanks to the heating resistance (figure 1.b, about $8 \Omega$ at $20^{\circ} \mathrm{C}$ ) screen-printed on the back side of the alumina substrate.

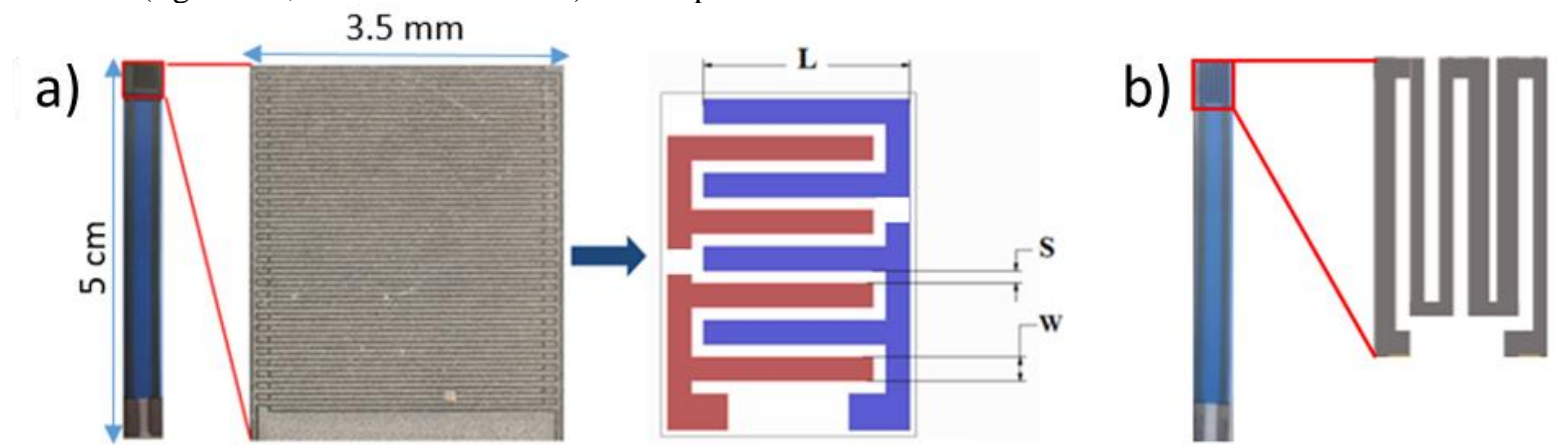

Figure. 1: Geometrical sensor parameters a) sensitive element (schematic representation) b) heating element (8 Ohms at $20^{\circ} \mathrm{C}$ ) 
Validation of the sensors fabrication process, consisting to check that the electrodes geometry is compliant with the one expected and reproducible, is made by comparison of the theoretical cell constants calculated according to the Olthuis model (Olthuis et al., 1995) with those measured experimentally.

The cell constant $(\kappa)$ is a geometry dependent parameter that links the sensor conductance $(\mathrm{G})$ to the conductivity $(\sigma)$ of the electrolytic solution in which the sensor is dipped.

The experimental determination of cell constants has been performed by measuring the conductance of the sensors dipped in a Potassium Chloride $(\mathrm{KCl})$ electrolytic standard solution (VWR Chemicals 83608.260, lot number 17L134104) with a known conductivity $\sigma$ of $12.88 \pm 0.1 \mu \mathrm{S} . \mathrm{cm}^{-1}\left(25^{\circ} \mathrm{C} ; 0.1 \mathrm{~mol} / \mathrm{L} ; \mathrm{KCl}\right)$.

These measurements were performed thanks to a voltage divider using an AC voltage ( $200 \mathrm{mV}$ peak-to-peak) with a frequency of $5 \mathrm{kHz}$ and a resistance $\mathrm{R}_{0}$ of a known value $10 \pm 0.1 \mathrm{k} \Omega$ (Figure 2).

The voltage was applied between the two input electrodes, and the potential difference was measured across the added resistance $\mathrm{R}_{0}$ for each sensor by a Keithley 2001 Multimeter with a resolution of $10 \mathrm{nV}$.

The cell constant $\kappa\left(\mathrm{cm}^{-1}\right)$ was determined experimentally using the following formula:

$$
\kappa=\frac{\mathrm{G}}{\sigma}
$$

where $G$ is the measured conductance $(G=1 / R, \mu S)$ of the sensor dipped in the electrolytic solution of a conductivity $\sigma\left(\mu \mathrm{S} . \mathrm{cm}^{-1}\right)$.



Figure. 2: Experimental setup for measuring the cell constant of each sensor

\subsection{Sensor exposure to soot particles}

The aim of this experiment is to deposit soot particles onto the sensing element of the sensor under different polarization voltages and to measure the conductance evolution as a function of time, using the experimental test bench devoted to soot studies in our laboratory (see Figure 3).

Generated soot particles are representative, in terms of structure, size distribution and organic content (OC), with those produced during a fire involving fuels commonly encountered in the nuclear industry (Ouf et al., 2015).

The soot particles were generated using a mini-CAST burner (Jing 5201). The production of soot is based on a propane-air diffusion flame quenched by a nitrogen flow. The air, nitrogen and propane flowrates values define an operating point that can be modified to produce aerosols with different soot size distributions and chemical natures (Moore et al., 2014; Yon et al., 2015). The chosen operating point allowed generating soot with a small organic part, this latter being less conductive (Grondin et al., 2019). In the present study, the selected point is $\mathrm{Q}_{\mathrm{C} 3 \mathrm{H} 8}=3.6$ $\mathrm{L} / \mathrm{h}, \mathrm{Q}_{\text {oxidation air }}=90 \mathrm{~L} / \mathrm{h}$, and $\mathrm{Q}_{\text {dilution air }}=1200 \mathrm{~L} / \mathrm{h}$.

Prior to soot exposure, sensors were baked in a furnace at a temperature up to $850{ }^{\circ} \mathrm{C}$. Then the resistive sensor was placed downstream an oven, with the sensing side parallel to the stream direction. This orientation was justified in regards of the fire application where the sensors should be placed against a wall, parallel to it to avoid intrusive effect of the sensor itself. A K-type thermocouple was placed near the sensor to control the gas temperature. 
Before the signal acquisition, the gas temperature has to reach $150^{\circ} \mathrm{C}$ close to the sensor, thanks to a tubular oven and a regulation loop. To get this stabilized temperature, one hour was spent heating up the test bench.

The sensor signal was monitored continuously, using a LabVIEW( interface, by applying a polarization voltage between 0 and $20 \mathrm{~V}$ (DC) on the electrodes with a Keithley 6517 A electrometer. When considering samples with conductance higher than $1300 \mu \mathrm{S}$ (above the highest measurable conductance by the Keithley 6517A), a voltage divider $\left(\mathrm{R}_{\mathrm{b}}=1 \mathrm{k} \Omega\right)$ has been used to reach conductance up to $3000 \mu \mathrm{S}$.

While loading soot on the sensor, soot size distribution and number concentration were recorded with a Scanning Mobility Particulate Sizer (SMPS) consisting of a differential mobility analyzer (DMA; Model 3080 long, TSI Inc.) and a Condensation Particle Counter (CPC; Model 3775, TSI Inc.). Prior to the SMPS unit, the sample gas was diluted using 2 dilution systems (VKL 10 from PALAS) with an overall dilution factor of 100. The SMPS was operated with a sheath air flow of $3 \mathrm{~L} / \mathrm{min}$ and an aerosol flow of $0.3 \mathrm{~L} / \mathrm{min}$. Aerosols size distribution measurements with electrical mobility diameter ranging from 17.2 to $562.3 \mathrm{~nm}$ were measured every $140 \mathrm{~s}$ to monitor the aerosol generation stability.

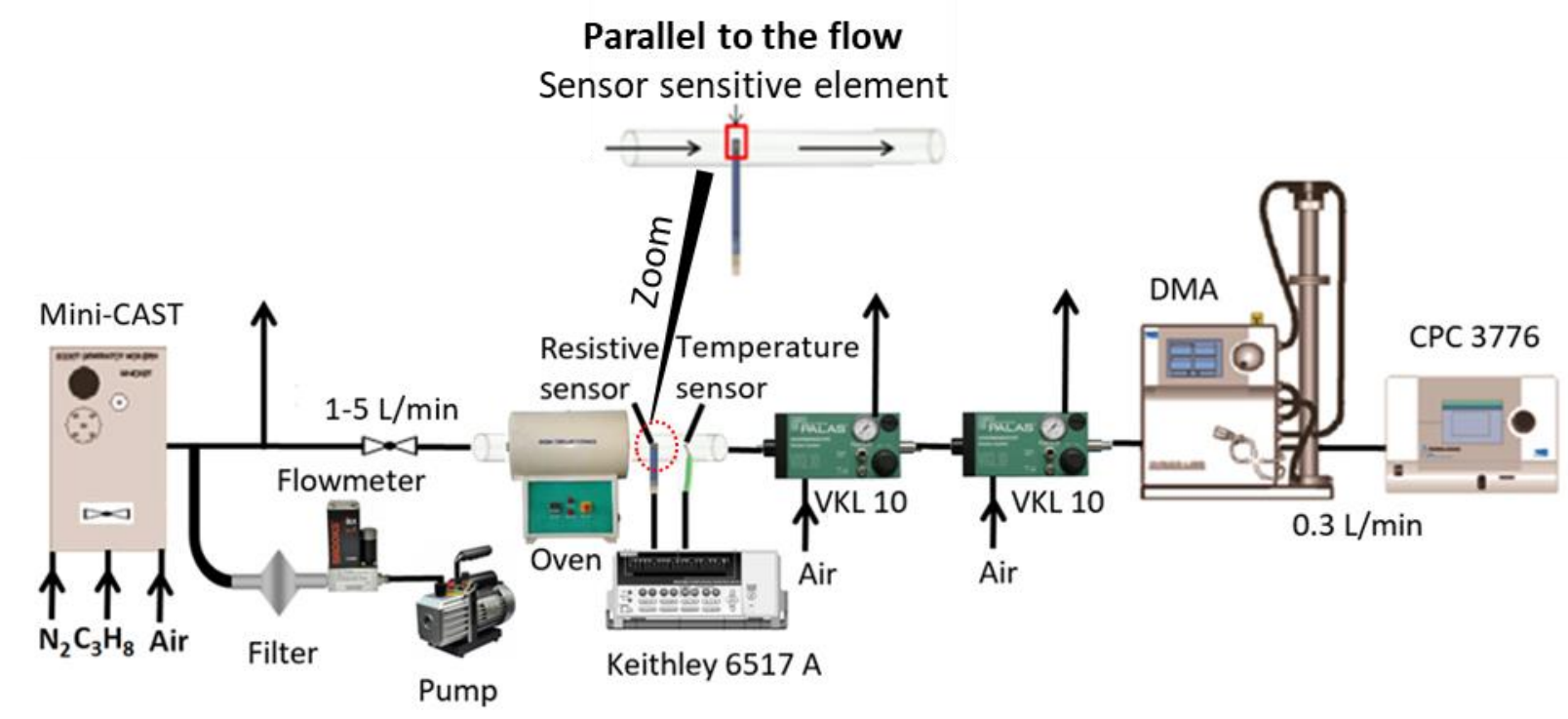

Figure 3: Experimental test bench used for soot deposition and characterization

During soot exposure, the number concentration and the median mobility diameter were also measured and found to be stable over time. Mean median electrical mobility diameter was equal to $208 \pm 20 \mathrm{~nm}$ with a geometric standard deviation of $1.6 \pm 0.1$ while the mean particulate number concentration was equal to $1.77 \times 10^{7} \pm 12 \%$ $\left(\# / \mathrm{cm}^{3}\right)$ after correction with a dilution factor of 100 .

To support the assumption that miniCAST soot particles could be used as a surrogate of real fire particles, comparison of size distribution obtained for the miniCAST with fire particles has been conducted prior to this study. For this purpose, soot produced by the combustion of an industrial solvent representative of a fire occurring in a nuclear waste treatment facility (Tributylphosphate (TBP) / Hydrogenated Tetrapropylene (TPH)) were characterized in terms of composition and size distribution. A good agreement regarding number concentration $\left(1.93 .10^{7} \pm 10 \% \# / \mathrm{cm}^{3}\right)$, mean median electrical mobility diameter $(216 \pm 15 \mathrm{~nm})$ and geometric standard deviation $(1.5 \pm 0.1)$ could be noticed with values reported for miniCAST soot. Considering previous study devoted to fire particles characterization (Ouf et al., 2015), and beyond the question of chemical composition, miniCAST soot particles could then be considered as a good surrogate, in terms of size distribution, of real fire particles.

\subsection{Protocol developed for the quantification of deposited mass of soot}

- Principle of carbon quantification

Soot particles are generally defined according to two main carbonaceous fractions, organic carbon (OC) that is a semi volatile component and elemental carbon (EC) that is formed by incomplete combustion and is a nonvolatile component (Petzold et al., 2013).

A semi-continuous Sunset Lab OC/EC field instrument (Sunset Laboratory) has been used for the quantification of particles deposited on the sensor sensitive area. In this case, the resistive sensor is directly placed within the tubular furnace of the OC/EC instrument. Measurement principle is based on thermal desorption of volatile organic content under inert atmosphere (helium) followed by the combustion of elemental carbon under oxidant 
atmosphere (oxygen/helium mixing). Carbon amount during each phase is then quantified by a Flame-IonizationDetector (FID) calibrated, in terms of carbon mass per sample surface area, to 4 sucrose standard solutions from 0.42 to $42 \mu \mathrm{g} . \mathrm{cm}^{-2}$. The IMPROVE A protocol (Chow et al., 2001) has been used to reduce the pyrolytic conversion of OC to EC. The amount of elemental carbon produced during this pyrolytic conversion of OC is generally subtracted from EC by monitoring laser transmittance through analyzed samples. Nevertheless, due to the resistive sensor opacity, the laser transmittance was not considered as a relevant pyrolytic conversion procedure. In the present case, this conversion has been carried out by considering the oxygen injection time for quantifying elemental and organic carbon (Birch \& Cary, 1996; Turpin et al., 1990).

Beyond the limitation of laser transmittance measurement through the sensor and potential influence on the organic carbon quantification, only mass of EC quantified by the thermo-optical analysis will be considered. To support this choice, OC/EC measurements have been performed for mini-CAST samples containing $10 \mathrm{mg}$ of soot deposited on quartz fiber filters (previously baked at $850^{\circ} \mathrm{C}$ for $1 \mathrm{~h}$, Pall Tissuquartz 2500 QAT-UP, $47 \mathrm{~mm}$ in diameter). Three punches of $1.5 \mathrm{~cm}^{2}$ were analyzed for each sample and a mean value of $\mathrm{EC} /(\mathrm{EC}+\mathrm{OC})=92 \pm 6 \%$ is reported. This low OC content (less than $10 \%$ ) is in agreement with previous results reported in the literature (Bescond et al., 2014) for the same operating conditions of the mini-CAST and supports the assumption of nearlypure EC soot samples. This approach may eventually conduct to under-estimation of total deposited mass for particles denoting complex composition. Nevertheless, by definition, soot particles are mostly composed of carbon atoms with a limited contribution of oxygen and hydrogen, supporting the relevance of this method of quantification of the soot deposited mass per surface area.

\section{- Quantification protocol of soot deposited mass on the sensor sensitive area}

During its exposure to soot particles, the resistive sensor entire surface (sensitive and non-sensitive) is subject to soot deposition. Then, it is necessary to develop an experimental protocol able to quantify soot particles deposited solely on the sensing area $\left(3.5 \times 3.5 \mathrm{~mm}^{2}\right)$. For this purpose, the non-sensitive surface of the sensor was cleaned using a Chemtronics ${ }^{\odot}$ micropoint cotton tip swab with a constant volume of $0.1 \mathrm{~mL}$ of ethanol (ethanol absolute anhydrous $99.9 \%$ from Carlo ERBA). Then, it was introduced in a furnace for $30 \mathrm{~min}$ at a temperature of $150{ }^{\circ} \mathrm{C}$ in order to remove any organic carbon contamination associated to the ethanol.

Moreover, additional biases could be reported during the quantification protocol. To evaluate their contribution to the measured value of deposited mass of carbon per surface area, EC/OC analyses have been performed on a nonexposed sensor according to the following conditions:

1) Residue: During OC/EC analysis, the sensor is subjected to temperature steps up to $850{ }^{\circ} \mathrm{C}$ aiming to remove soot particles from the sensor surface. Nevertheless, one may suspect a bias associated to residual soot particles even at the end of the analysis. Then, this bias has been quantified by measuring OC and EC content of a previously baked (up to $850^{\circ} \mathrm{C}$ ) sensor.

2) Residue + atmospheric pollution: in this second condition, OC/EC measurements are performed on previously baked sensors taken out of the furnace of the OC/EC instrument to mimic its handling in ambient air after soot exposition and prior to analysis.

3) Residue + atmospheric pollution + ethanol contribution: in this case, a cleaning phase using ethanol is added to the second condition. Sensor is then dried at $150^{\circ} \mathrm{C}$ for $30 \mathrm{~min}$ and $\mathrm{OC} / \mathrm{EC}$ measurements have been performed.

Three OC/EC measurements have been performed for each of these conditions and average values are reported in table 1. For convenience, the deposited mass per surface area is expressed in $\mathrm{mg} / \mathrm{m}^{2}$, considering the carbon mass quantified by the OC/EC instrument (expressed in $\mu \mathrm{g}$ ) and the area of the sensor sensitive surface $\left(12.25 \mathrm{~mm}^{2}\right)$.

Table 1: Quantification of biases associated to the deposited mass measurement protocol

\begin{tabular}{|c|c|c|c|}
\hline \multirow{2}{*}{ Carbon fraction } & \multicolumn{3}{|c|}{ Deposited mass per surface area $\left(\mathrm{mg} / \mathrm{m}^{2}\right)$} \\
\cline { 2 - 4 } & Residue & $\begin{array}{c}\text { Residue+ Atmospheric } \\
\text { pollution }\end{array}$ & $\begin{array}{c}\text { Residue+ Atmospheric } \\
\text { pollution + Ethanol } \\
\text { contribution }\end{array}$ \\
\hline EC & $19 \pm 2$ & $74 \pm 7$ & $118 \pm 5$ \\
\hline OC & $554 \pm 13$ & $660 \pm 6$ & $864 \pm 33$ \\
\hline
\end{tabular}

As expected, and even after drying in a furnace during 30 minutes at $150^{\circ} \mathrm{C}$, a significant contribution of $\mathrm{OC}$ was reported from the overall process (residue+ atmospheric contribution + ethanol contribution). Nevertheless, and 
as previously mentioned, EC fraction is only considered since soot produced by the Mini-CAST are considered as nearly-pure EC samples.

Regarding biases associated to EC, a maximum cumulative bias of $118 \pm 5 \mathrm{mg} / \mathrm{m}^{2}$ was reported for the entire analysis protocol. Then, this bias was subtracted from our measurement of EC carbon mass per surface area associated to exposed sensors.

\section{RESULTS AND DISCUSSIONS}

\subsection{Cell constants measurement}

In order to test the reliability of the resistive sensors fabrication process, 10 sensors were manufactured. After the fabrication, the sensor cell constants were individually determined thanks to conductance measurement in a standard electrolytic solution (see figure 2). Experimentally, the characterization procedure consisted in making 3 consecutive conductance measurements of each sensor dipped in the electrolytic solution, at room temperature $\left(25^{\circ} \mathrm{C}\right)$. The cell constants were then calculated according to equation (1). Experimental cell constants values of $0.23 \mathrm{~cm}^{-1} \pm 0.5 \%$ ( uncertainty calculated from the standard deviation on all 3 repeatability measurements for the 10 sensors) showed a good agreement with theoretical value calculated according to Olthuis' model (Olthuis et al., 1995). A mean theoretical cell constant value of $0.21 \mathrm{~cm}^{-1} \pm 10 \%$ (uncertainty induced by the determination of the geometric characteristics) has been calculated for the 10 sensors. A variation less than $1 \%$ has been noticed between the cell constants due to geometrical uncertainties and a good agreement is also reported with experimental cell constants. A good reproducibility was found for the 10 sensors confirming the reliability of the fabrication process.

\subsection{Influence of the polarization voltage on the deposition velocity}

To study the influence of the polarization voltage on the deposition velocity, the sensor was exposed to soot particles during $600 \mathrm{~s}$ using the test bench (figure 3 ) and for voltage ranging from 0 to $20 \mathrm{~V}$. Then, the experimental protocol described previously for soot deposition and carbon quantification was applied.

As mentioned above, only the EC content is considered to determine the deposited mass on the sensing face and a bias of $118 \mathrm{mg} / \mathrm{m}^{2}$ is subtracted from the EC deposited mass per surface determined by the OC/EC analyzer.

For each polarization voltage varying from 0 to $20 \mathrm{~V}$, three measurements have been conducted. Using these EC deposited mass after $600 \mathrm{~s}$, the deposition flux $\mathrm{F}_{\mathrm{d}}\left(\mathrm{mg} / \mathrm{m}^{2} \mathrm{~s}\right)$ is calculated by taking into account the sensing surface area of the resistive sensor. The deposition velocity of soot particles on the resistive sensor surface $\operatorname{area} \mathrm{v}_{\mathrm{d}}(\mathrm{m} / \mathrm{s})$ is then determined using equation 2 :

$$
\mathrm{v}_{\mathrm{d}}=\frac{\mathrm{F}_{\mathrm{d}}}{\mathrm{C}_{\mathrm{a}}}
$$

with $\mathrm{C}_{\mathrm{a}}$ the mass concentration of soot particles in the aerosol phase $\left(\mathrm{mg} / \mathrm{m}^{3}\right)$.

In order to measure the mass concentration, soot collection was taken on quartz filters (Quartz Membranes 2500 QAT - UP) diameter $37 \mathrm{~mm}$ in a stainless steel filter holder.

This filter holder is isolated from the sampling line by a manual valve which allows the installation and removal of the filter during the experiments. A Brooks ${ }^{\circledR}$ flowmeter is connected between the filter holder and the pump for air flow regulation at a sampling flow rate of $4 \mathrm{~L} / \mathrm{min}$.

The mass concentration $\mathrm{C}_{\mathrm{a}}$ in the bench under standard conditions $\left(\mathrm{T}_{\mathrm{S}}=20^{\circ} \mathrm{C}\right.$ and $\left.\mathrm{P}_{\mathrm{S}}=1013 \mathrm{hPa}\right)$, is expressed by the relationship:

$$
\mathrm{C}_{\mathrm{a}}=\frac{\Delta \mathrm{m}}{\mathrm{V}_{\mathrm{s}}}=\frac{\Delta \mathrm{m}}{10^{-3} \cdot \mathrm{t} \cdot \mathrm{Q}_{\mathrm{s}}},
$$

with $\Delta \mathrm{m}$ the mass of the deposited soot $(\mathrm{mg}), \mathrm{V}_{\mathrm{S}}$ the sampled volume brought to standard conditions $\left(\mathrm{m}^{3}\right.$ at $20^{\circ} \mathrm{C}$ and $1013 \mathrm{hPa}), \mathrm{Q}_{\mathrm{S}}$ the sampling rate under standard conditions $\left(\mathrm{L} / \mathrm{min}\right.$ at $20^{\circ} \mathrm{C}$ and $1013 \mathrm{hPa}$ ) and the sampling time (min). The mass concentration is equal, after $30 \mathrm{~min}$ of sampling, to $83.3 \mathrm{mg} / \mathrm{m}^{3}$ (average of 6 measurements).

Figure 5 shows the evolution of the deposition velocity as a function of the polarization voltage.

The uncertainties of the deposition velocity is calculated using the propagation of error (equation 4):

$$
\mathrm{u}\left(v_{d}\right)=\sqrt{\left(\frac{1}{\mathrm{C}_{\mathrm{a}}}\right)^{2} \mathrm{u}\left(\mathrm{F}_{\mathrm{d}}\right)^{2}+\left(\frac{\mathrm{F}_{\mathrm{d}}}{\left(\mathrm{C}_{\mathrm{a}}\right)^{2}}\right)^{2} u\left(C_{a}\right)^{2}}
$$




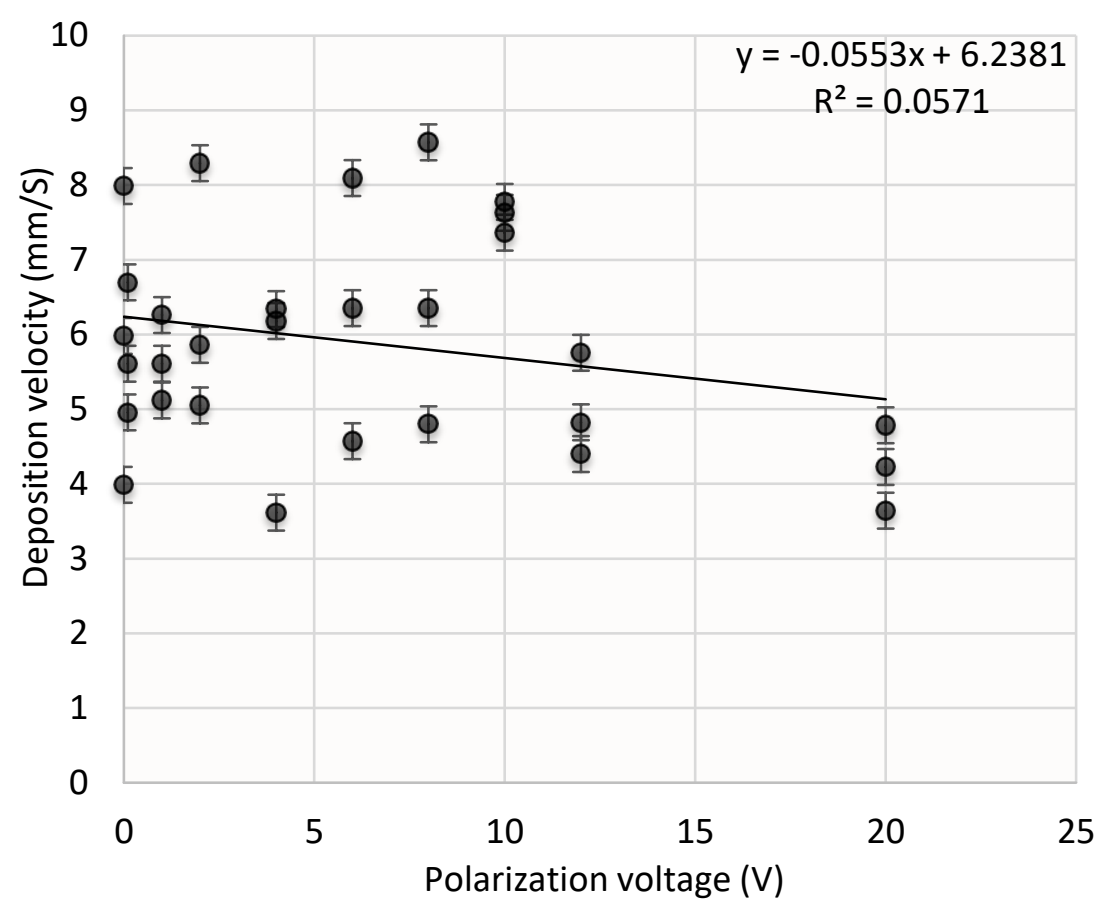

Figure 5: Influence of the polarization voltage on the deposition after 600 s exposure

A higher dispersion has been found for deposition velocities measured below $10 \mathrm{~V}$ compared to those for $10 \mathrm{~V}$, $12 \mathrm{~V}$ and $20 \mathrm{~V}$. This dispersion can be explained by the "pure percolation" deposition mode characterized by a random process of deposit structuration and low polarization voltage (close to $0.1 \mathrm{~V}$ ). The deposition velocities, ranging from nearly 4 to $9 \mathrm{~mm} / \mathrm{s}$, are lower than those reported by Brugière et al., (2014), ranging from 16 to 19 $\mathrm{mm} / \mathrm{s}$ for soot deposition mainly driven by thermophoresis. This discrepancy, in terms of deposition velocities, can be explained by significantly higher temperature gradient imposed by Brugière et al., (2014) $(50750 \mathrm{~K} / \mathrm{m})$ in comparison with our experimental conditions $(15000 \mathrm{~K} / \mathrm{m})$.

A linear regression allows finding a slope of $-0.05 \mathrm{~mm} / \mathrm{s} . \mathrm{V}$ with a standard deviation of $0.04 \mathrm{~mm} / \mathrm{s}$.V (same order of magnitude as the slope). The slope obtained, in our case, is close to zero and its standard deviation is almost $100 \%$ of its value. Therefore, it haven't been able to demonstrate that polarization voltage has a significant effect on the deposition velocity.

\subsection{Influence of the polarization voltage on the electrical sensor response}

In addition to the demonstration of the non-measurable effect of polarization voltage on the deposited mass per surface area, the effect of polarization voltage on the dynamic response of the resistive sensor have been also studied. Figure 6 presents the time evolution of the conductance recorded for the same sensor at polarization voltages between 0.1 and $10 \mathrm{~V}$ and during similar exposure to soot particles during $600 \mathrm{~s}$.

Conductance was then recorded during the $600 \mathrm{~s}$ of exposure for each polarization voltage and sensor was, then, regenerated in the OC/EC instrument.

Left hand side of figure 6 presents evolution of sensor conductance as a function of time and for polarization voltage ranging from 0.1 to $10 \mathrm{~V}$. 

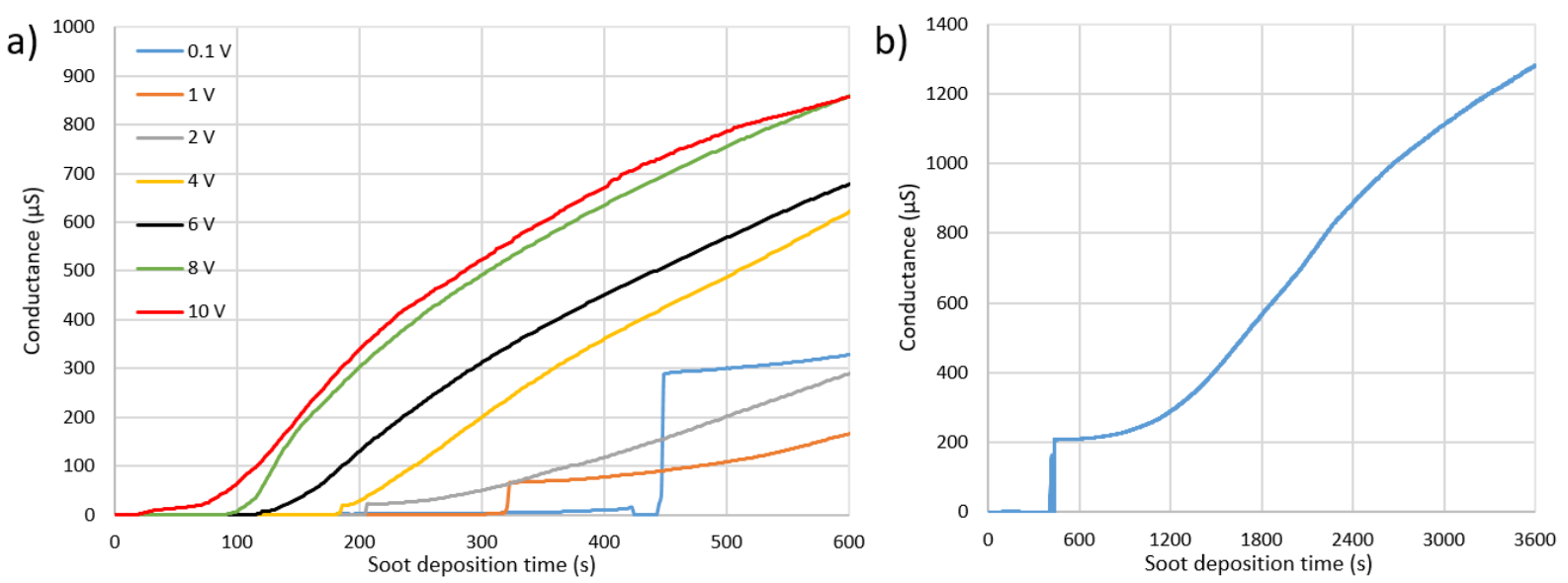

Figure 6: Sensor responses a) under different polarization voltages during 600 s exposure; b) under 0.1 volt during 3600 s exposure

For low polarization (i.e. null or lower than $0.1 \mathrm{~V}$ in our case), a sudden increase of conductance is observed after $400 \mathrm{~s}$ of soot deposition time. In this case, electrostatic forces are not predominant and do not force soot particles to be well aligned between sensor electrodes. In this case, soot deposition occurs homogeneously and randomly at the active sensor surface without any soot bridges formation between electrodes. Then, the deposit is not structured for low polarization voltage (corresponding to electrical field of $5000 \mathrm{~V} / \mathrm{m}$ for a polarization voltage of $0.1 \mathrm{~V}$ and a gap of $20 \mu \mathrm{m}$ between two electrodes) and the creation of junctions between the electrodes will be ruled by "percolation" (Da Silva Leite Coelho et al., 2017) defined by a sharp increase of conductance (as reported in figure 6 for $0.1 \mathrm{~V}$ ) when a first pathway is formed for electric conduction.

Between $0.1 \mathrm{~V}$ and $6 \mathrm{~V}$ (corresponding to electrical field ranging between 5000 and $300000 \mathrm{~V} / \mathrm{m}$ ), an intermediate regime is observed and characterized by a sharp increase of conductance, followed by continuous evolution which leads to a sigmoidal shape curve even for a polarization voltage of $0.1 \mathrm{~V}$ when experiment is pursued after $600 \mathrm{~s}$ (figure 6.b). This sigmoidal shape curve has been obtained for all applied polarization voltages.

The sharp step and time to reach this step observed for those voltages are dispersed (figures 8), but increase as the polarization voltage tends towards lower voltage.

For polarization voltages higher than $6 \mathrm{~V}$ (corresponding to an electric field of $300000 \mathrm{~V} / \mathrm{m}$ ), the conductance increases more continuously. In agreement with results of (Li et al., 2016) who reported full alignment of nearly $200 \mathrm{~nm}$ soot particles in an electric field of $600000 \mathrm{~V} / \mathrm{m}$, the significant electric field between the sensor electrodes tends also to align soot particles, leading to the growth of several dendrites in parallel and in quasi perfect alignment with the electrical field. Then, continuous increase of conductance corresponds to the formation of such dendrites, which successively form bridges between the electrodes. Such bridge formations appear to be repeatable over the time and is ruled by electrical field larger than $300000 \mathrm{~V} / \mathrm{m}$ in the "dendritic" regime, as shown in SEM observation reported in figure $7 \mathrm{~b}$.

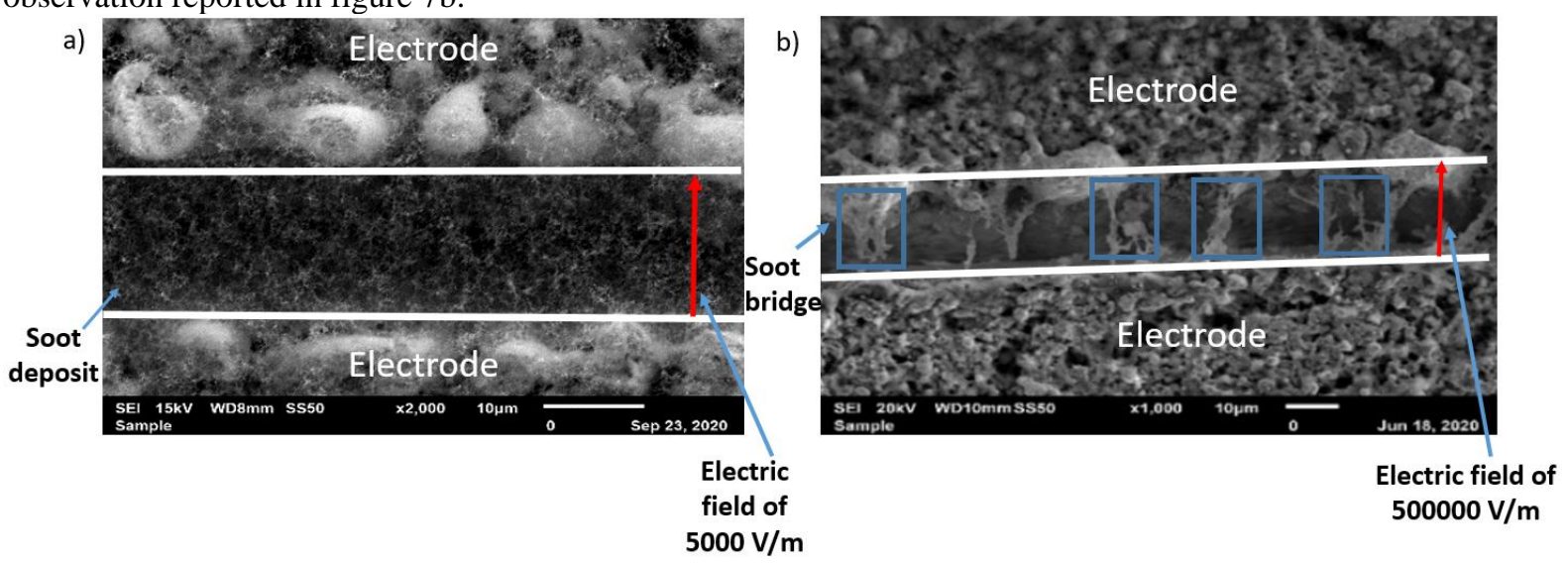

Figure 7: SEM image of soot deposits between the resistive sensor electrodes under a) $0.1 \mathrm{~V}$ and b) $10 \mathrm{~V}$ of polarisation voltage after $1 \mathrm{~h}$ of exposition 
To go further, the question of reproducibility of the sensors response has been investigated for the polarization voltages of $0.1 \mathrm{~V}$ and $10 \mathrm{~V}$. Three tests have been performed on a same sensor under similar exposure conditions and for each polarization voltage. Figure 8 represents the conductance evolution for 3 successive tests at $10 \mathrm{~V}$ and $0.1 \mathrm{~V}$ for the same sensor.

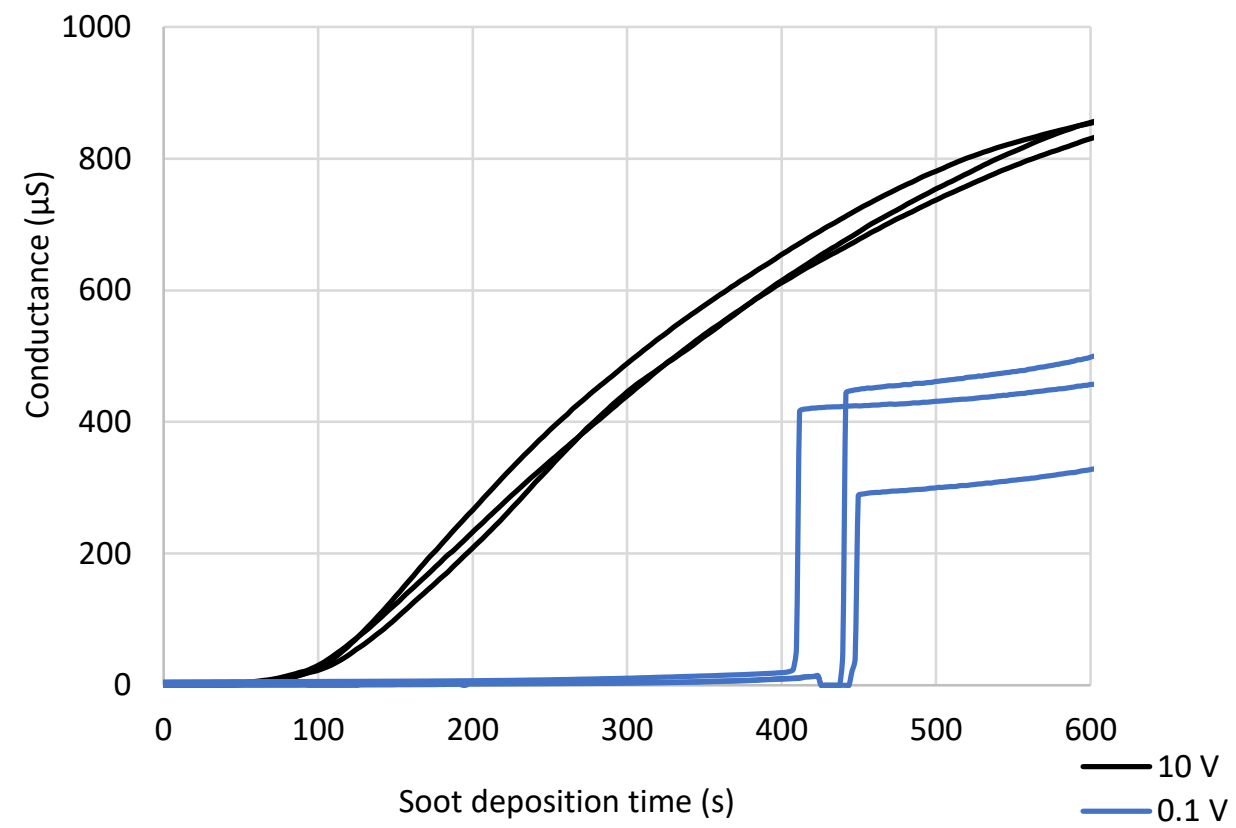

Figure 8: Conductance measurement during soot deposition experiment under polarization voltages of $0.1 \mathrm{~V}$ and $10 \mathrm{~V}$

Comparing the 3 successive responses of the sensor at a polarization voltage of $0.1 \mathrm{~V}$, before an exposure time of $400 \mathrm{~s}$, it can be seen that the sensor response is less repeatable. This can be explained by the fact that, at this polarization voltage, the electric field has a poor influence on the deposit, inducing a less-reproducible deposit before the first connection between electrodes and therefore a poor reproducibility in the height and the time of appearance of the conductance step.

At a polarization voltage of $10 \mathrm{~V}$, moderate dispersion between conductance evolutions reported for successive measurements could be noticed confirming the overall repeatability of the process of soot bridges formation on the sensor sensing face for this polarization voltage. These observations are also supported by the morphology of the deposited soot, either randomly for $0.1 \mathrm{~V}$, or well-structured for $10 \mathrm{~V}$ (figure 7).

The deposition mechanism on the sensor could be due to thermophoresis (Fragkiadoulakis et al., 2018) but the soot bridges structures can only be explained by the strong electrical field imposed between the electrodes (up to $500000 \mathrm{~V} / \mathrm{m}$ for a polarization voltage of $10 \mathrm{~V}$ ). Consequently, the calibration curve is assumed to be independent from the deposition mechanisms and relevant for all these mechanisms.

\subsection{Calibration of the resistive soot sensor}

- Evolution of conductance and deposited mass according to soot deposition time

For calibration reasons, it is important to be able to continuously link the soot mass deposit to the conductance. For this purpose, two extreme cases were chosen: one associated to repeatable and reproducible conductance $(10 \mathrm{~V})$ and another one associated to poorly repeatable/reproducible conductance evolution $(0.1 \mathrm{~V})$.

EC deposited mass was measured for reached conductance up to $3000 \mu \mathrm{S}$. For each conductance considered, three measurements of deposited mass have been performed on the same sensor under similar conditions.

The EC deposited mass per surface area and the conductance as a function of the soot deposition time when applying a polarization voltage of $10 \mathrm{~V}$ and $0.1 \mathrm{~V}$ is represented in figure 9. 




Figure 9: Evolution of the EC deposited mass and the conductance as a function of soot deposition time (a zoom in the range 0 to $800 \mathrm{~s}$ is proposed in lower right part)

Both curves for $0.1 \mathrm{~V}$ and $10 \mathrm{~V}$, respectively for mass and conductance, exhibit similar trends which confirms, as shown in figure 9, that the polarization voltage has no significant influence on deposited mass and conductance once the percolation time is reached $(\mathrm{t}>400 \mathrm{~s}$ for $0.1 \mathrm{~V})$. The main difference is the higher dispersion of measured data for $0.1 \mathrm{~V}$ as previously explained.

For short deposition time $(\mathrm{t}<100 \mathrm{~s}$ for $10 \mathrm{~V}, \mathrm{t}<200 \mathrm{~s}$ for $0.1 \mathrm{~V})$, the conductance remains close to 0 and increases very slowly confirming the beginning of bridge construction (percolation period). During this period, the deposited mass was not measured due to the detection limit of OC/EC instrument.

Then, the conductance increases according to a sigmoidal evolution (as also clearly shown on figure 8 for $10 \mathrm{~V}$ polarization) attributed to the soot bridge construction versus time. A quantitative modeling of such curves has been proposed by (Grondin et al., 2019) and it was shown, for a polarization voltage of $30 \mathrm{~V}$, that the conductance asymptotic behavior is reached when the deposit thickness is higher than 1.5 inter-electrodes space. The deposit thickness $\mathrm{Z}$ is calculated using (equation 5) (Thomas et al., 2014) :

$$
\frac{\mathrm{dZ}}{\mathrm{d} m_{s}}=\frac{1}{\rho_{p} \cdot(1-\varepsilon)},
$$

by assuming a deposit porosity $\varepsilon$ of $95 \%$ (the porosity represents the ratio between the volume of void in the deposit and the total volume of the deposit) and a density of $1650 \mathrm{~kg} / \mathrm{m}^{3}$ (Ouf et al., 2019). According to equation 2 and for a mass deposit of $m_{s}=230 \mathrm{mg} / \mathrm{m}^{2}$, a thickness of $2.8 \mu \mathrm{m}$ is computed, demonstrating the beginning of bridge formation under this condition. On the other hand, for $m_{s}=1630 \mathrm{mg} / \mathrm{m}^{2}$, the deposit thickness reaches a value of $19.8 \mu \mathrm{m}$, close to the inter-electrodes space $(20 \mu \mathrm{m})$, confirming that the sensor behavior is not yet in the asymptotic regime reported by Grondin et al., (2019).

Finally, the objective is to correlate mass deposit with the sensor conductance.

- Correlation between the sensor conductance and the EC deposited mass

Conductance results are reported as a function of EC deposited mass per surface in Figure 10 for polarization voltages of $10 \mathrm{~V}$ and $0.1 \mathrm{~V}$. 


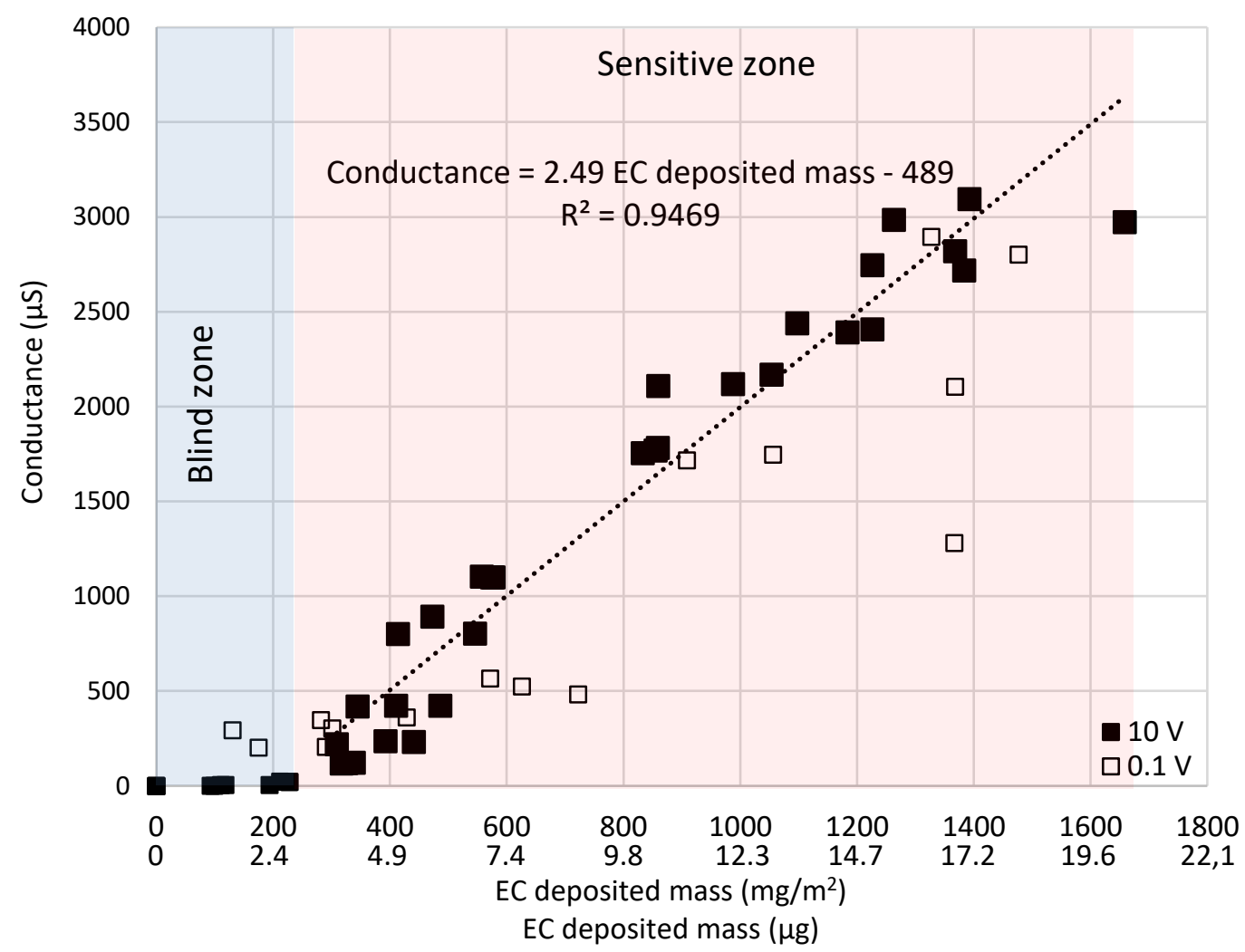

Figure 10: Correlation between the conductance and the EC deposited mass

As expected from previous results, a large dispersion of results obtained with $0.1 \mathrm{~V}$ makes it difficult to build a calibration curves in such conditions.

However for $10 \mathrm{~V}$, the obtained curve can be divided into two trends:

$>$ A first trend when the mass is lower than $230 \mathrm{mg} / \mathrm{m}^{2}$ where conductance remains close to zero. This area corresponds to the beginning of bridge building (as demonstrated by previously computed thickness deposit of $2.8 \mu \mathrm{m}$ ). As soot is deposited, many bridges start to form, but as most of them are not yet fully built (no or low rate connections between electrodes), their overall contribution to any conductance increase remains weak. In this zone, the sensor has no significant sensitivity.

$>$ A second trend is observed in the range $230-1630 \mathrm{mg} / \mathrm{m}^{2}$ of deposited soot. An almost linear relation between EC deposited mass and sensor conductance can be seen, indicating that conductance (bridges formation) increases proportionally with soot deposited mass. In this zone, the sensor sensitivity is significant and equal to $2.49 \pm 0.18 \mu \mathrm{S} \cdot \mathrm{mg}^{-1}$. $\mathrm{m}^{2}$.

This results point out that, if the polarization voltage is adequate, the resistive soot sensor can be calibrated with a linear dependency to monitor the deposited mass.

\section{CONCLUSION AND OUTLOOK}

The aim of this work was to study the influence of the polarization voltage on the deposited mass and to propose a relation at a relevant polarization voltage between the conductance and the deposited mass. To reach these two objectives, resistive sensors have been specifically manufactured.

The cell constants of 10 sensors have been calculated theoretically and measured experimentally using a standard electrolytic solution. Theoretical cell constants are in close agreement with experimental ones, confirming the reliability of the fabrication process and the precise description of the geometrical structure of this resistive sensor. Two specific protocols have been developed and qualified for measuring the time evolution of the deposited mass of soot and the conductance after soot exposure. For this purpose, mass quantification was carried out, after several cleaning steps, using a thermo-optical analyzer for mass quantification. To the best of our knowledge, present developments are the first to be applied for the quantification of carbonaceous particles deposited on sensor surface. This protocol has been used to demonstrate that the polarization voltage has no measurable effect on the deposited mass per surface area but has a significant influence on the structure of soot deposit formed at the sensor surface. Such variation of deposit structure has been confirmed by the time evolution of conductance for different polarization voltages. Three regimes have been introduced according to polarization voltage, "pure percolation" (polarization voltage lower than $0.1 \mathrm{~V}$ ), "intermediate" for voltage between 0.1 and $6 \mathrm{~V}$ and "dendritic" for voltage higher than $6 \mathrm{~V}$. In pure percolation regime, soot deposit is not guided by the electric field and is formed randomly at the active surface of the sensor. For high voltages ("dendritic" regime), the electric field influence on the 
structure of the deposit is predominant and the soot deposit occurs in the form of dendrites parallel to the electric field.

The "intermediate regime" is characterized by sharp increase of conductance associated to homogeneous deposit of soot particles over the entire sensor surface. In this regime, electric field is not sufficient to form perfectly aligned soot bridges within the electrodes but significantly influences the deposit structure. The two extreme regimes, with polarization voltages of $10 \mathrm{~V}$ and $0.1 \mathrm{~V}$, have been selected for further calibration. A calibration curve has been obtained for a polarization voltage of $10 \mathrm{~V}$ while it haven't been able to propose similar curve for $0.1 \mathrm{~V}$ due to less repeatable and reproducible conductance evolution. Two zones were identified during the $10 \mathrm{~V}$ calibration. A first one, with EC mass deposited and conductance respectively lower than $230 \mathrm{mg} / \mathrm{m}^{2}$ and $20 \mu \mathrm{S}$, where the sensor is "blind", i.e. it has no significant sensitivity. A second one, within an EC and conductance range higher than $230 \mathrm{mg} / \mathrm{m}^{2}$ and $20 \mu \mathrm{S}$, respectively, where the sensor observed a linear behavior between EC deposited mass and conductance with a sensitivity around $2.49 \mu \mathrm{S} . \mathrm{mg}^{-1} \cdot \mathrm{m}^{2}$.

Major conclusion of this study remains on the non-intrusive behavior of the resistive sensor regarding soot deposition mechanism for the applied polarization voltages. Furthermore, soot deposit structure has been demonstrated to be ruled by this polarization voltage. For these two reasons, we believe that calibration curve proposed in this study could be considered despite the deposition mechanism.

Nevertheless, and for real fire conditions, higher deposition velocities could be encountered, inducing higher deposition flux and, as a consequence, shorter time for reaching asymptotic behavior of the resistive sensor associated to lower sensitivity. To go further, it will be necessary to develop a complementary measurement approach to extend the deposited mass range.

This is a first step for quasi real-time quantification of soot deposition on walls during fires depending on the nature of soot and on the location of the sensor in the fire room. Then, the second prospect of this study deals with the influence of soot particles (size distribution, composition, morphology...) emitted during complex fire situations (real fuels, ventilation and residence time in the fire room) on the resistive sensor response and its calibration curve.

\section{REFERENCES}

Bartscherer, P., \& Moos, R. (2013). Improvement of the sensitivity of a conductometric soot sensor by adding a conductive cover layer. J. Sens. Sens. Syst, 2, 95-102. https://doi.org/10.5194/jsss-2-95-2013

Bellivier, A., Copalle, A., Loo, A., Yon, J., Decoster, L., Dupont, S., \& Bazin, H. (2015). Comparison and Assessment of Particle Mass Concentration Measurements in Fire Smokes with a Microbalance, Opacimeter and PPS Devices. Fire Science and Technology, 735-742. https://doi.org/10.1007/978-981-10-0376-9_75

Bescond, A., Yon, J., Ouf, F. X., Ferry, D., Delhaye, D., Gaffié, D., Coppalle, A., \& Rozé, C. (2014). Automated determination of aggregate primary particle size distribution by tem image analysis: Application to soot. Aerosol Science and Technology, 48(8), 831-841. https://doi.org/10.1080/02786826.2014.932896

Birch, M. E., \& Cary, R. A. (1996). Elemental carbon-based method for monitoring occupational exposures to particulate diesel exhaust. Aerosol Science and Technology, 25, 221-241.

Bourrous, S., Bouilloux, L., Ouf, F. X., Lemaitre, P., Nerisson, P., Thomas, D., \& Appert-Collin, J. C. (2016). Measurement and modeling of pressure drop of HEPA filters clogged with ultrafine particles. Powder Technology, 289(109), 117. https://doi.org/10.1016/j.powtec.2015.11.020

Brugière, E., Gensdarmes, F., Ouf, F. X., Yon, J., \& Coppalle, A. (2014). Increase in thermophoretic velocity of carbon aggregates as a function of particle size. Journal of Aerosol Science, 76, 87-97. https://doi.org/10.1016/j.jaerosci.2014.06.007

Brunel, O., Duault, F., Lavy, J., Creff, Y., \& Youssef, B. (2013). Smart Soot Sensor for Particulate Filter OBD. SAE International Journal of Passenger Cars - Electronic and Electrical Systems. https://doi.org/10.4271/2013-01-1334

Campbell, R. (2018). Fires in Industrial and Manufacturing Properties. www.nfpa.org/101

Chesser, R. K., \& Rodgers. B.E. (2008). Near-field radioactive particle dynamics and empirical fallout patterns in Chernobyl's Western and Northern Plumes. Atmospheric Environment, 42(20), 5124-5139. https://doi.org/https://doi.org/10.1016/j.atmosenv.2008.02.042

Chow, J. C., Watson, J. G. Crow, D., Lowenthal, D. H., \& Merri, T. (2001). Comparison of IMPROVE and NIOSH Carbon Measurements. Aerosol Science and Technology, 34, 23-34.

Da Silva Leite Coelho, P. H., De Deus Armellini, V. A., \& Morales, A. R. (2017). Assessment of percolation threshold simulation for individual and hybrid nanocomposites of carbon nanotubes and carbon black. Materials Research, 20(6), 1638-1649. https://doi.org/10.1590/1980-5373-MR-2016-1084

Evangeliou, N., Zibtsev, S., Myroniuk, V., Zhurba, M., Hamburger, T., Stohl, A., \& Kireev, S. I. (2016). Resuspension and atmospheric transport of radionuclides due to wildfires near the Chernobyl Nuclear Power Plant in 2015: an impact assessment. In Sci. Rep. 6 (1) (Vol. 26062). https://doi.org/10.1038/srep26062

Feulner, M., Hagen, G., M??ller, A., Schott, A., Z??llner, C., Br??ggemann, D., \& Moos, R. (2015). Conductometric sensor for soot mass flow detection in exhausts of internal combustion engines. Sensors (Switzerland). https://doi.org/10.3390/s151128796

Floyd, J., Overholt, K., \& Ezekoye, O. (2014). Soot deposition and gravitational settling modeling and the impact 
of particle size and agglomeration. Fire Safety Science. https://doi.org/10.3801/IAFSS.FSS.11-376

Fragkiadoulakis, P., Geivanidis, S., \& Samaras, Z. (2018). Modeling a resistive soot sensor by particle deposition mechanisms. Journal of Aerosol Science. https://doi.org/10.1016/j.jaerosci.2018.06.005

Gelain, T., Richard, J., \& Khanchali, F. (2018). Evaluation des modèles de transport et de dépôt implémentés dans les codes 0D et CFD pour des conduits à échelle industrielle. Congrès Français Sur Les Aérosols.

Grondin, D., Breuil, P., Viricelle, J. P., \& Vernoux, P. (2015). Development of a particulate matter sensor for diesel engine. Procedia Engineering. https://doi.org/10.1016/j.proeng.2015.08.838

Grondin, D., Breuil, P., Viricelle, J. P., \& Vernoux, P. (2019). Modeling of the signal of a resistive soot sensor, influence of the soot nature and of the polarization voltag. Sensors and Actuators, B: Chemical, 298. https://doi.org/https://doi.org/10.1016/j.snb.2019.126820

Grondin, D., Geara, S., Breuil, P., Viricelle, J. P., \& Vernoux, P. (2016). Influence of Electrodes Polarization on the Response of Resistive Soot Sensor. Procedia Engineering. https://doi.org/10.1016/j.proeng.2016.11.124

Hagen, G., Spannbauer, C., Feulner, M., Kita, J., Müller, A., \& Moos, R. (2018). Conductometric soot sensors: Internally caused thermophoresis as an important undesired side effect. Sensors (Switzerland), 18(10). https://doi.org/10.3390/s18103531

Kaltofen, M., \& Gundersen, A. (2017). Radioactively-hot particles detected in dusts and soils from northern japan by combination of gamma spectrometry, autoradiography, and SEM/EDS analysis and implications in radiation risk assessment. Science of the Total Environment, 607, 1065-1072. https://doi.org/doi:10.1016/j.scitotenv.2017.07.091

Li, M., Mulholland, G. W., \& Zachariah, M. R. (2016). The effect of alignment on the electric mobility of soot. Aerosol Science and Technology, 50(10), 1003-1016. https://doi.org/10.1080/02786826.2016.1213789

Mensch, A., \& Cleary, T. (2018). A Soot Deposition Gauge for Fire Measurements. NIST Technical Note 1985. https://doi.org/10.6028/NIST.TN.1985

Moore, R. H., Ziemba, L. D., Dutcher, D., Beyersdorf, A. J., Chan, K., Crumeyrolle, S., Raymond, T. M., Thornhill, K. L., Winstead, E. L., \& Anderson, B. E. (2014). Mapping the operation of the miniature combustion aerosol standard (Mini-CAST) soot generator. Aerosol Science and Technology, 48(5), 467479. https://doi.org/10.1080/02786826.2014.890694

Ohno, T., Tashiro, S., Amano, Y., Yoshida, R., \& Abe, H. (2020). Rapid Clogging of High-Efficiency Particulate Air Filters During In-Cell Solvent Fires at Reprocessing Facilities. Nuclear Technology, 206(1), 40-47. https://doi.org/10.1080/00295450.2019.1620057

Olthuis, W., Streekstra, W., \& Bergveld, P. (1995). Theoretical and experimental determination of cell constants of planar-interdigitated electrolyte conductivity sensors. Sensors and Actuators B, B 24-25, 252-256.

Ouf, F.-X., Mocho, V.-M., Pontreau, S., Wang, Z., Ferry, D., \& Yon, J. (2015). Physicochemical properties of aerosol released in the case of a fire involving materials used in the nuclear industry. Journal of Hazardous Materials, 283, 340-349. https://doi.org/10.1016/j.jhazmat.2014.09.043

Ouf, F. X., Bourrous, S., Fauvel, S., Kort, A., Lintis, L., Nuvoli, J., \& Yon, J. (2019). True density of combustion emitted particles: A comparison of results highlighting the influence of the organic contents. Journal of Aerosol Science, 134, 1-13. https://doi.org/10.1016/j.jaerosci.2019.04.007

Petzold, A., Ogren, J. A., Fiebig, M., Laj, P., Li, S. M., Baltensperger, U., Holzer-Popp, T., Kinne, S., Pappalardo, G., Sugimoto, N., Wehrli, C., Wiedensohler, A., \& Zhang, X. Y. (2013). Recommendations for reporting black carbon measurements. Atmospheric Chemistry and Physics, 13(16), 8365-8379. https://doi.org/10.5194/acp-13-8365-2013

Reynaud, A. (2019). Compréhension et modélisation des mécanismes de captation des aérosols par couplage des phénomènes aérodynamiques et électriques. Université de Lyon.

Reynaud, A., Leblanc, M., Zinola, S., Breuil, P., \& Viricelle, J.-P. (2019). Responses of a Resistive Soot Sensor to Different Mono-Disperse Soot Aerosols. In Sensors. https://doi.org/10.3390/s19030705

Riahi, S. (2012). Development of Tools for Smoke Residue and Deposition Analysis. the Faculty of The School of Engineering and Applied Science of The George Washington University in partial satisfaction of the requirements for the The George Washington University.

Thomas, D., Ouf, F. X., Gensdarmes, F., Bourrous, S., \& Bouilloux, L. (2014). Pressure drop model for nanostructured deposits. Separation and Purification Technology. https://doi.org/10.1016/j.seppur.2014.09.032

Turpin, B. J., Cary, R. A., \& Huntzicker, J. J. (1990). An un-situ time resolved analyzer for aerosol organic and elemental carbon. Aerosol Science and Technology, 12(161-171).

Yon, J., Bescond, A., \& Ouf, F. X. (2015). A simple semi-empirical model for effective density measurements of fractal aggregates. Journal of Aerosol Science, 87, 28-37. https://doi.org/10.1016/j.jaerosci.2015.05.003 